\title{
20. DEEP-SEA TURBIDITES FROM THE WESTERN PACIFIC: LEG 7, DEEP SEA DRILLING PROJECT
}

\author{
G. R. Heath, Department of Oceanography \\ Oregon State University, Corvallis, Oregon \\ and \\ Ralph Moberly, Jr., Hawaii Institute of Geophysics, \\ University of Hawaii, Honolulu, Hawaii
}

\begin{abstract}
Turbidites from a volumetrically minor portion of the predominantly pelagic sediments cored on Leg 7. Nevertheless, they provide valuable information on the sedimentary regime and stability of high areas around the drill sites. For example, they indicate heightened tectonism in the Marshall Island area 35 to 45 million years ago. They also profoundly influence the acoustic character of the sedimentary layer by acting as strong reflectors in otherwise homogenous sections.
\end{abstract}

\section{INTRODUCTION}

All Leg 7 drill sites are separated from major land masses by effective topographic traps, such as the Mariana Trench, or by great distances. As a result, turbidite sequences of the abyssal-plain type were neither anticipated nor encountered. At Sites 65, 66 and 67 , however, sediments which appeared to have been emplaced by bottom-following density currents were cored.

\section{SITE 65}

Above 124 meters, the sediment at Site 65 consists of uniform siliceous ooze, with a single 5-centimeter graded bed ( 1 millimeter at base to 0.1 millimeter at top) at 76 meters. The components of this bed include palagonite, silicified clay lumps, ferromanganese micronodules and siliceous spicules, which probably slumped from the side of the large submarine ridge lying between Site 65 and the Marshall Islands.

Below 124 meters, thin layers of exotic lithologies occur throughout the section of unconsolidated siliceous ooze. The thin beds (usually less than 10 centimeters) include abundant and often close packed sand grains, ranging up to 2 millimeters in diameter. These coarser layers are usually silicified, and cover the full spectrum from slightly indurated sands to quartzite-like porcelanites and sandy cherts. The only features common to the silicified beds are concentrations of coarse particles (including volcanic debris in most cases) and higher original permeability than the enclosing sediments. Either of these features could aid in the silicification process, although the enhanced permeability is probably of primary importance.
The coarse grained rocks are usually laminated (1 to 2 millimeter layers). In a few cases, crude grading and truncated low-angle cross-bedding testify to the influence of bottom currents at the time of deposition.

In the simplest case, the coarse grains in each lamina consist entirely of close-packed, well sorted tests of foraminifera. The absence of other sand-sized grains, and the fine detail preserved in the calcite tests (even in the molds formed by post-depositional silicification) suggest that this sediment originated in an area of rapid biogenous deposition well above the contemporary calcite compensation depth. Transport to Site 65 and subsequent burial occurred so rapidly that negligible solution of the tests took place.

Most of the coarse layers contain a much greater variety of sand-sized grains. Thin section descriptions accompanying the Site 65 summary contain detailed lists of some of these assemblages. In general, the assemblages originally accumulated in areas of slow deposition, below the contemporary calcite compensation depth. Thus, they generally include phosphatic fish debris, ferromanganese micronodules, and altered volcanic debris, all indicative of slow deposition. The absence of razor edges on glass shards indicates that alteration at least partly predated transport to Site 65 . Other common framework grains include clay lumps (probably indurated fecal pellets in most cases), foraminiferal tests and siliceous spicules and radiolarian tests. Fragments of composite grains attest to partial induration of the parent deposits before displacement and transport to Site 65 .

The general bathymetry of the western Central Basin, and the distribution of subbottom reflectors on the 
Seismic profiler records taken between the Marshall Islands and Site 65 suggest that the coarse layers were emplaced by turbidity currents from the west. Many of the flows probably originated at the north-south ridge immediately west of Site 65 . Others, however, may have come from the slopes of the Marshall Islands.

The concentration of turbidites in the upper Eocene and lower Oligocene part of the section probably results from heightened tectonic and perhaps volcanic activity along the ridges west of Site 66 between 35 and 45 million years ago.

\section{SITE 66}

Although the sediment column at Site 66 is strikingly similar to that at Site 65 , only one sample showed clear evidence of current activity at the time of deposition. This sample is a yellow-brown porcelanite consisting of graded laminae up to 5 millimeters thick. Micro-erosional contacts and intraformational fragmentation of some laminae are further evidence of an energetic depositional environment.

The framework grains in this rock are dominantly Radiolaria, with rare phosphatic fish debris and ferromanganese micronodules. The same constituents make up the enclosing siliceous ooze, suggesting that the graded deposit could have been derived from the immediiate vicinity of Site 66 .

The distribution of reflectors in seismic profiler records from the area around Site 66 suggests that turbidites derived from the Line Islands ridge are present in most of the valleys. The drill site, on a small rise, failed to intersect any of these deposits.

\section{SITE 67}

Because of the limited core recovery at this site, and the disturbed nature of the recovered sediments, only the broadest conclusions can be drawn as to past sedimentation regimes.

The effects of strong bottom currents, probably including turbidity currents, are preserved in contacts between laminated epiclastic volcanic sandstones and zeolitic mudstones. The upper surfaces of the sandstone have been grooved and otherwise eroded prior to deposition of the mudstones. Unlike the "turbidites" of Sites 65 and 66, the mudstones of Site 67 do not display obvious grading. Thus, emplacement may have been by high density slumping, rather than via more conventional "turbidity currents" (monodispersed autosuspensions).

\section{CONCLUSIONS}

Even though the sedimentary sections at Leg 7 sites are dominated by pelagic deposits, the influence of bottom currents in introducing exotic components and altering sediment properties cannot be ignored. In particular, volumetrically insignificant turbidites, like those at Site 65, may profoundly modify seismic profiler records, without markedly influencing either the thickness of dominant character of the sedimentary section. 